\title{
Gender, sexual diversity and field education: "in rural communities many people do not understand and treat it as a disease"
}

\author{
Gênero, diversidade sexual e educação do campo: "nas \\ comunidades rurais muitas pessoas não entendem e \\ tratam como doença"
}

\section{Género, diversidad sexual y educación de campo: "en las comunidades rurales muchas personas no lo entienden y tratan como una enfermedad"}

\author{
Thaynara Oliveira da Silva \\ ORCID: https://orcid.org/0000-0002-9318-8254 \\ Universidade do Estado da Bahia, Juazeiro, Bahia, Brasil \\ E-mail: inara.18@hotmail.com \\ Pedro Paulo Souza Rios \\ ORCID: https://orcid.org/0000-0001-7981-9091 \\ Universidade do Estado da Bahia, Senhor do Bonfim, Bahia, Brasil \\ E-mail: peudesouza@yahoo.com.br
}

\section{ABSTRACT}

The present study aimed to discuss issues of gender, sexual diversity, gender diversity and Rural Education. The (auto) biographical narratives were used as the methodological path, and the narrative interview as an instrument of data collection, allowing the interviewees to narrate their life story, placing themselves as protagonists of the investigation process. Thus, we emphasize that the interviewees were two gay university students, who live in the countryside. From the study, the need to problematize the dialogue around issues of gender and sexual diversity in Rural Education was noticeable. It is necessary to break binary schemes around issues that involve sexuality, mature reflections around queer bodies, aiming in fact to know how these issues are addressed in the training processes of rural communities and how much, through these processes, can be done in the sense to contribute to acceptance, I respect the plurality that exists among society, in order to decolonize / deconstruct the rules imposed and taken as standards.

Keywords: Gender; Sexual diversity; Homosexuality; Rural education. 


\section{RESUMO}

0 presente estudo teve por objetivo discorrer acerca das questões de gênero, diversidade sexual, diversidade de gênero e Educação do Campo. Foram utilizados como percurso metodológico as narrativas (auto)biográficas, e a entrevista narrativa como instrumento de coleta de dados, permitindo aos entrevistados narrar sua história de vida, se colocando como protagonista do processo de investigação. Assim, salientamos que os entrevistados foram dois estudantes universitários gays, que moram na zona rural. A partir do estudo ficou perceptível a necessidade de problematizar o diálogo em torno das questões de gênero e diversidade sexual na Educação do Campo. Sendo necessário romper esquemas binários em torno das questões que envolvem a sexualidade, amadurecer reflexões em torno dos corpos queer, visando de fato saber como essas questões são abordadas nos processos formativos das comunidades rurais e o quanto, através desses processos, pode ser feito no sentido de contribuir para a aceitação, respeito a pluralidade existente entre a sociedade, com o intuito de descolonizar/desconstruir as normas impostas e tidas como padrões.

Palavras chave: Gênero; Diversidade sexual; Homossexualidade; Educação do campo.

\section{RESUMEN}

El presente estudio tuvo como objetivo discutir temas de género, diversidad sexual, diversidad de género y Educación Rural. Se utilizaron las narrativas (auto) biográficas como camino metodológico, y la entrevista narrativa como instrumento de recolección de datos, permitiendo a los entrevistados narrar su historia de vida, ubicándose como protagonistas del proceso de investigación. Así, destacamos que los entrevistados fueron dos universitarios homosexuales, que viven en el campo. A partir del estudio, se notó la necesidad de problematizar el diálogo en torno a temas de género y diversidad sexual en la Educación Rural. Es necesario romper esquemas binarios en torno a temas que involucran la sexualidad, madurar reflexiones en torno a cuerpos queer, buscando de hecho saber cómo se abordan estos temas en los procesos de formación de las comunidades rurales y cuánto, a través de estos procesos, se puede hacer en el sentido para contribuir a la aceptación, respeto la pluralidad que existe entre la sociedad, para descolonizar / deconstruir las reglas impuestas y tomadas como estándares.

Palabras clave: Género; Diversidad sexual; Homosexualidad; Educación rural.

\section{INTRODUÇÃO}

Desde o nascimento do movimento feminista que temas relacionadas a liberdade sexual, sexualidade, respeito as diferenças, equidade de gênero, orientação e diversidade sexual, dentre outros tem permanecido em evidência. Contudo, é importante ressaltar que tais informação não chegam na mesma maneira a todos os lugares, o que pressupõe dizer que tais discussões ainda precisam estabelecer conexões com outras áreas do conhecimento, a saber Educação do Campo.

Assim, o presente artigo buscou discorrer acerca das questões de gênero, diversidade sexual, diversidade de gênero e Educação do Campo, refletindo sobre suas intersecções, por considerarmos que as mesmas ainda são pouco discutidas, sobretudo nos espaços formativos da Educação do Campo, a saber a escola, fazendo-se necessário potencializar esse diálogo. De acordo com Rios (2016), as questões relacionadas e esses temas ainda são tomados como tabu, deixando à margem de tais reflexões uma gama importante da população, os sujeitos do campo.

Salientamos que é perceptível o quanto as discussões em torno das questões de gênero e diversidade sexual têm assegurado cada vez mais espaços de discussão, ficando em evidencia na academia por meio de pesquisas, nas mídias televisivas e escritas, conquistando e garantindo a efetivação de direitos historicamente negados. No entanto, faz-se necessário que 
as mesmas cheguem a lugares que foram historicamente tomadas como não espaços de construção dos saberes.

Sobre isso Fischer (2006), argumenta que mesmo reconhecendo a importância dos povos do campo os mesmos só participam do processo de construção social quando se trata do fazer prático, da mão de obra braçal. As questões inerentes a suas identidades e subjetividades foram e ainda são negligenciadas. Assim, as temáticas de gênero, sexualidade, diversidade sexual pouco são discutidas na perspectiva dos povos que habitam o campo. Rios (2016), argumenta que tais temas são devem ser privilégios de alguns/mas, ao contrário, se queremos pensar em uma sociedade equitativa e respeite as diferenças devemos problematizar tais questões em todas as esferas.

Historicamente as discussões de gênero e diversidade sexual estavam atreladas apenas sobre a construção do ser mulher e do ser ou homem. Enfatizando as relações de poder de um sexo/gênero sobre o outro, ressaltando que sexo se refere ao órgão biológico feminino e masculino e gênero é como a pessoa se reconhece independente do seu órgão sexual, a partir de padrões sociais sexista que impõe normas, tornando-os determinantes sobre comportamentos, relacionamentos, profissões, enfim, sobre o modo de viver ditando o que é certo ou errado.

Tendo padrões pré-definidos, um modelo a ser seguido, sendo este, homem, heterossexual, branco, rico, bem eurocêntrico, onde o capitalismo faz questão de propagar/ disseminar. De acordo com Louro (2014), para que se compreenda o lugar e as relações de homens e mulheres numa sociedade importa observar não exatamente seus sexos, mas sim tudo o que socialmente se construiu sobre seus sexos.

No decurso das problematizações inerentes a equidade de gênero e suas intersecções, além das dicotomias sobre ser mulher/homem, heterossexual/homossexual, outros temas foram suscitados, evidenciando principalmente a diversidade sexual constituída nos corpos, sendo chamado de estudos Queer. Trazendo para as discussões aqueles/as tomados/as como estranhos/as. Ou seja, aqueles/as que se colocam contra a normalização (Louro, 2018), seja de sexo, orientação, étnica, estética ou qualquer outra norma que busque padronizar.

Perceber os corpos queer, respeitando as diferenças, sendo eles mulheres, homens, heterossexual, homossexual, travesti, transexual, da cidade, do campo, do quilombo, dos movimentos, da igreja, do terreiro e dentro de todas as suas pluralidades precisa ser o centro das discussões. Compreender a identidade de cada sujeito, plurais e múltiplas e sendo na maioria das vezes contraditórias. De acordo com Louro (2014, p. 29) afirma que o gênero constitui a identidade do sujeito, bem como etnia, a classe, ou a nacionalidade, dentre outras.

Os processos educativos, sejam eles escolares ou não estão perpassados por diferenças, sejam elas construídas ou legitimadas nos próprios espaços. "Diferenças, distinções, desigualdades [...]. A escola entende disso. Na verdade, a escola produz isso" (Louro, 2014, p. 61). E quando nos remetemos aos espaços educativos silenciadas essas diferenças podem ser ainda mais perceptíveis, a saber as escolas do campo, para as quais o acesso ao conhecimento às distintas áreas do conhecimento é negado, por ser considerado o lugar contrário ao mito do progresso da humanidade (Benjamim, 1985). Partindo desse princípio, os saberes a serem ensinados nas escolas do campo serão aqueles inerentes ao fazer prático. Assim, o conhecimento que diz respeito ás subjetividades, como sexualidade, corpo, corporeidade, orientação sexual, diversidade de gênero, dentre outros serão silenciados.

Desde a sua constituição a escola assume papel importante na formação dos sujeitos, vindo depois da família como a instituição responsável pela construção e formação da identidade, colocando-a como algo fixo e acabado, atendendo a um sistema capitalista que visa apenas o lucro e desconsidera a realidade/identidade dos sujeitos, deixando à margem aqueles que estão fora da "norma". Uma educação que considere as identidades plurais, a realidade dos sujeitos, faz-se necessária. 
Por isso, partiremos da reflexão em torno das questões de gênero e diversidade sexual, e como tais discussões emergiram, evidenciando os corpos tidos como transgressores socialmente e dentro dos espaços formativos, em especial percebendo esses corpos na perspectiva dos processos escolares a partir da Educação do Campo. 0 presente estudo é de abordagem qualitativa, tendo como método as narrativas biográficas e as entrevistas narrativas como instrumento de coleta de dados.

\section{METODOLOGIA}

Considerando o caráter formativo desse estudo, entendemos que metodologia narrativa biográfica é a que melhor contribuirá na compreensão do fenômeno por nós aqui estudado. Ademais, entendemos que a mesma possibilita melhor compreensão da realidade dos sujeitos, sendo possível compreender emoções a partir de sua história de vida.

No campo das narrativas pesquisadores como Nóvoa (2000), Josso (2006) e Souza (2006), dentre outros, têm apresentado trabalhos significativos nessa área, que versam desde a constituição do educador reflexivo até a formação inicial e continuada dos profissionais da educação.

0 estudo apresenta o método biográfico, a partir da entrevista narrativa. A entrevista narrativa favorece àquele/a que narra maiores possibilidades de expressão, desvelando por meio dos gestos, da voz, dos espaços de tempo atribuído entre as palavras, fazendo emergir momentos, lugares, pessoas, acontecimentos adormecidos na memória (Rios \& Dias, 2020, p.4).

É importante ressaltar que o estudo foi realizado com dois estudantes do Campus VII, da Universidade do Estado da Bahia - UNEB. Sendo um discente do curso de Bacharelado em enfermagem, residente em uma comunidade quilombola do campo, Cazumba, pertencente ao município de Senhor do Bonfim. O outro é estudante do curso de licenciatura em Pedagogia, residente numa comunidade rural Sitio do Meio, município de Andorinha. Ressaltamos ainda que a utilização desse método vislumbra colocar o sujeito na posição de protagonista de sua formação e do processo de investigação (Santos \& Garms, 2014).

A entrevista ocorreu entre os dias 15 a 19, levando em consideração a disponibilidade dos entrevistados. Salientamos que a gravação da narrativa ocorreu por meio do aplicativo WhatsApp, devido ao atual momento onde passamos por uma pandemia mundial conhecida como COVID-19, sendo necessário algumas medidas de proteção, dentre elas o isolamento social (Brasil, 2020). 0 entrevistado gravou áudios com sua narrativa.

Num primeiro momento, houve uma conversa acerca do assunto, sobre como seria feita a narrativa explicando o objetivo do estudo e todos os assuntos a serem discorridos durante a entrevista, principalmente para esclarecer quais dúvidas do entrevistado e também deixá-lo mais à vontade para narrar. Em seguida, foi apresentado o Termo de Livre Consentimento Esclarecido - TLCE e enviado por e-mail, para ser devidamente assinado e devolvido; permitindo o uso da narrativa e deixando-o ciente sobre a metodologia que seria seguida.

A seguir faremos uma breve apresentação do entrevistado para que os/as leitor/as conheçam, entendam quem é, sua trajetória de vida e formação, possibilitando uma melhor reflexão e compreensão da pessoa entrevistada com os/as teóricos/as. Ao ser questionado sobre como deveria ser chamado durante a escrita da narrativa os entrevistados optaram por usar os seus próprios nomes, seguido como sobrenome o local da comunidade em que reside, sendo assim: Gustavo Cazumba e Natan do Sítio os nomes dos nossos entrevistados.

Em sua narrativa Gustavo Cazumba se apresentou da seguinte maneira: "[...] Gustavo é uma pessoa de uma comunidade quilombola. Tenho 20 anos, estou começando a me descobrir agora, se sou gay, se sou bi, se sou pan... Também sou estudante de enfermagem na UNEB campus VII" (Gustavo Cazumba, 2020). Mesmo não tendo sido gravada presencialmente, foi possível perceber que Gustavo Cazumba ficou à vontade para falar das suas vivências enquanto gay oriundo da Educação do Campo. 
Natan do Sítio se apresentou da seguinte maneira: "Sou um jovem sonhador e batalhador. Mora na zona rural, sou gay, estudante de pedagogia, mas durante minha infância estudei na roça mesmo. Esse sou eu, mas não sou só isso". Pelos áudios encaminhados por Natan do Sítio foi possível perceber certo desconforto para falar das suas experiências relacionadas a sexualidade quando ainda estudava na escola do campo, conforme ele mesmo ressaltou: "Essa questão de sexualidade não ainda é difícil para mim, mas estou superando aos poucos”.

Essa breve apresentação dos nossos entrevistados é importante para compreender fatos e momentos narrados a partir de suas vivências, mesmo considerando que não é possível abarcar todas as vivências inerentes às suas experiências por meio das entrevistas narrativas. Contudo, as mesmas nos possibilitam tecer comentários acerca da temática em questão.

\section{RESULTADOS}

\section{Gênero e diversidade sexual: "algo que precisa sim ser trabalhado na educação do campo"}

No Brasil, de maneira mais incisiva nas últimas duas décadas alguns pesquisadores têm se debruçado sobre estudos que enfatizam com profundidade o impacto da discriminação de gênero e por orientação sexual na educação (Seffner, 2009; Junqueira, 2013; Caetano, 2016; Rios \& Dias, 2019, 2020). Mesmo considerando que tais estudos ainda sejam incipientes, não podemos desconsiderar sua relevância e qualidade junto aos movimentos sociais e na academia, uma vez que os mesmos fornecem elementos teóricos que sinalizam a escola brasileira como um importante espaço de produção e reprodução de modelos e normas pautados em atitudes e comportamentos preconceituosos e discriminatórios em relação a mulheres e homossexuais ou qualquer outra forma de viver e manifestar a diferença.

Estudos ainda sinalizam que a heterossexualização compulsória (Buttler, 2003) se faz acompanhar pelo silenciamento e violência contra pessoas que transgridem as normas vigentes, por meio da rejeição da homossexualidade e por comportamentos que expressam comportamento homofóbicos (Louro, 1999). Compreendemos, portanto, que a homofobia produz efeitos sobre todo aquele/a que a sofre, no ambiente escolar não é diferente, uma vez que a escola se configura enquanto espaço privilegiado os processos de constituição de sujeitos e de produção de identidades heterossexuais produzem e alimentam a homofobia e o sexismo, especialmente entre os jovens estudantes masculinos (Rios, Dias \& Brasão, 2019). Para os/as que defendem a heteronormatividade compulsória, o/a outro/a, especialmente, gays, transexuais, travestis, para fazerem valer suas masculinas e heterossexuais, deverão a todo momento demostrar que exorcizaram de si mesmos a feminilidade e a homossexualidade (Louro, 2018).

A manifestação de ações homofóbicas ficam ainda mais acentuadas de acordo com Natan Sítio (2020), nas escolas do campo:

A gente pode perceber que a homofobia está presente em todo lugar, até onde não deveria tá, no meu ponto de vista, que é a escola, mas ela tá lá também ... como é que eu posso dizer... assim, se ela tá nas escolas da cidade, que a gente pensa que os professores já discutem esses temas imagina nas escolas da roça. Ser gay na roça é muito mais difícil. E a escola que poderia ser um espaço pra gente falar sobre isso não é.

A partir da narrativa descrita acima é possível inferir que a Educação do Campo precisa avançar muito nas questões inerentes a diversidade sexual, respeito às diferenças, equidade de gênero e suas intersecções. Pensar as práticas educativas sejam em escolas do campo ou da cidade pressupõe necessariamente assegurar o direito à liberdade e a expressão de gênero e orientação sexual. De acordo com Rios e Dias (2020), o currículo precisa assegurar que todas as questões que dizem respeito à formação subjetiva dos sujeitos sejam contemplados. 
A Educação do Campo se constitui enquanto proposta educativa ancorada na Lei de Diretrizes e Bases da Educação Nacional - LDBEN No 9.394/96. Segundo esta, é necessário que os conteúdos curriculares e metodologias estejam apropriados às reais necessidades e interesses dos/as alunos/as da zona rural (Lemos et al., 2015, p. 5). Gustavo Cazumba relata sobre como foi sua educação na comunidade onde reside:

Bom, quando eu comecei a estudar aqui no Cazumba foi com quatro anos. Eu entrei na creche, era uma creche que era tipo uma parceria de lá da Itália, tipo uma associação de lá da Itália, tinha tipo uns padrinhos, a gente, pequeno, tinha os padrinhos e a gente estudava lá. Depois fui para a escola municipal daqui do Cazumba. Era uma turma multisseriada da primeira até a quarta série, era um pouco complicado porquê era um professor só pra quatro turmas e uma sala só, de certa forma isso atrapalha um pouco no nosso desenvolvimento por ser apenas um professor né e era tipo crianças daqui do Cazumba I, Cazumba II, de Lagoinha e Boutiquinho, era uma turma muito cheia e era um só professor, isso atrapalhava um pouco (Gustavo Cazumba, 2020).

A narrativa de Gustavo Cazumba nos faz refletir sobre o processo educativo daquela comunidade, em como se dava essa organização da turma multisseriada, e em como seria para aquela professora atender a todas essas comunidades. Levando em consideração que isso ocorreu há alguns anos, tendo em vista que hoje diante de tantas conquistas, processos formativos melhores para estes profissionais ainda é difícil lecionar em classes multisseriadas e descolonizando esses sujeitos. Nessa mesma perspectiva Natan Sítio (2020), relata sua experiência ainda na Educação Infantil:

Quando comecei a estudar na comunidade não tinha uma sala só para crianças, a Educação Infantil, só para a gente... então a gente estudava com outros menin os maiores e isso não era bom, pelo menos hoje eu percebo que não. Sempre davam as mesmas atividades para a gente fazer, pintar e repetir cópia de atividades que a professora trazia numa folha, hoje eu não vejo o sentido, sem falar que não tinha da nossa realidade.

Compreender as identidades como algo construído socialmente e se é construído, pode sim ser modificado (Scoot, 2005). Pensar o território do Semiárido em todas as suas nuances é perceber as nuances de gênero presentes no território. A imagem da mulher, dona de casa, mãe, dedicada aos afazeres e cuidados da família. Aquela que aos olhos da sociedade era recatada e do lar, que no Semiárido tinha mais uma tarefa árdua de ajudar na lavoura para o sustento da família; já o homem, marido, trabalhava fora de casa, sempre no meio público, distante de casa. Nesse contexto problematizar outras maneiras de viver a sexualidades se configurava como algo inaceitável, ainda que tais sexualidades transitassem nos distintos espaços sociais. Sobre isso Paiva e Barros (2017, p. 15) comenta:

[...] Observamos que, hoje, multiplicaram-se os modos de compreender, de dar sentido e de viver, os gêneros e a sexualidade no espaço social, que têm sido ignorados e/ou escondidos pelo próprio ambiente escolar por argumentos essencialmente morais, seguindo uma tendência. Nesse solo, o grande desafio é romper com os esquemas binários de gênero (homem-mulher) e da sexualidade (heterossexual-homossexual) e aceitar as múltiplas posições que estão sendo delineadas na sociedade...

Romper com os binarismos de gênero e sexualidade, ainda silenciados, histórico e socialmente, nas escolas, nas famílias e ainda apegadas a estereótipos que devem ser superados. Nesse sentido, Gustavo Cazumba (2020), argumenta:

É muito importante trabalhar sexualidades nessas escolas aqui do campo, as crianças e os adolescentes eles não entendem isso, a gente chega nos lugares, eles ficam tipo cochichando, 
rindo, achando estranho porque eles não sabem. Os pais não conversam sobre isso, na escola também não conversa sobre isso. A gente sai em um final de semana para ir em uma festa, uma comunidade aqui vizinha, chega lá todo mundo está de boa e aí fica o povo fuxicando até os idosos, os mais velhos, as pessoas mais velhas quando vê fica comentando e botando apelido como se fosse algo anormal. Porque tipo, para eles pode até ser algo anormal porque eles não presenciam, mas não é uma anormalidade, não é uma doença, não é!

Na fala de Gustavo Cazumba e a partir das reflexões colocadas anteriormente por Paiva e Barros (2017), percebemos o quanto fica evidente a necessidade de desconstrução/ descolonização em torno das questões de gênero e diversidade sexual, arraigados ainda ao modelo binário. Na narrativa de Natan Sítio (2020), também é possível constar a necessidade de repensar tais questões. Ressalta ele:

Depois de tudo que vivi, como posso dizer isso? Depois do que vivi quando ainda era criança, enquanto estudava, só porque era diferente dos meus colegas, era mais sensível, me aproximava mais das meninas, gostava de ficar mais com elas e essas coisas que crianças gays gostam... posso garantir que a gente precisar mudar nossa prática educativa, nas escolas do campo principalmente, só assim a gente vai ter meninos gays mais resolvidos com sua sexualidade.

Ainda que de maneira há o preconceito de que a zona rural é lugar do atraso. A essa concepção equivocada os sujeitos eram considerados como atrasados, fazendo com que a educação a eles direção seja constituída na perspectiva da compensação, pois "trata os sujeitos do campo como incapazes de tomar suas próprias decisões". Entende que estes "são sujeitos que apresentam limitações, em função das poucas oportunidades que tiveram em sua vida e do pouco conhecimento que tem" (Hage, 2005, p.14). A essa concepção se juntava também elementos ligados a sexualidade, gênero, orientação sexual dentre outros. Nessa perspectiva, Gustavo Cazumba ressalta que:

As questões sobre sexualidade não eram de jeito nenhum trabalhado, eu acho até porque as professoras tinham medo de discutir isso nas salas porque os pais aqui eram um pouco ignorantes, eu me lembro que tinha confusão direto, os pais iam lá brigar. Lembro até que quando eu fui estudar em Bonfim, teve uma mãe que ela era da zona rural e aí, porque no livro tinha sobre os preservativos, a mãe foi lá reclamar e a gente teve que trocar de livro porquê mostrava o órgão genital masculino e feminino (Gustavo Cazumba, 2020).

A escola vê-se ameaçada. Os modelos, as fórmulas, as certezas mostram-se inúteis, escampam diante dos "novos" sujeitos que transitam no seu interior, não há como ignorar. Os educadores/as, se sentem desafiados, perplexos, instáveis, de fato sem saber o que fazer e como proceder diante das diversidades (Louro, 2018).

Esse diálogo precisa acontecer, principalmente dentro da escola para depois adentrar as comunidades. A escola enquanto instituição formadora deve aproximar esses diálogos, valorizando a construção das mais diferentes identidades, não somente a de gênero e diversidade sexual, mas a campesina, de raça, religiosidade, dentre tantas outras, possibilitando o desenvolvimento de uma formação política e crítica desses sujeitos.

Nesse sentido, a descolonização do saber contribui com a formação de consciências críticas, capazes de recriar a dinâmica e as relações sociais opressivas as quais os sujeitos estão submetidos (Lemos et al., 2015, p. 5). A educação não muda o mundo, a educação muda os sujeitos e eles mudam o mundo em que vivem, a partir da sua realidade, fazendo novas construções, percebendo todos/as a sua volta e dando voz aqueles/as que sempre foram de alguma maneira silenciados/as. 
Sob esse prisma é importante saliente que a Educação do Campo nasce em contraposição ao modelo educacional hegemônico. Seu objetivo é o fortalecimento da identidade camponesa, a retomada da função social e política da escola. Lemos et al. (2015), saliente que as diversidades de gênero e sexuais também atravessam a identidade camponesa, como ficou notório a partir da entrevista de Gustavo Cazumba, além da necessidade de aproximação e discussão dessa intersecção, tendo a escola como peça fundamental na promoção dessas desconstruções e descolonização.

Louro (2018), ainda nos chama atenção sobre a teoria queer, nos permite "pensar a ambiguidade, a multiplicidade e a fluidez das identidades sexuais e de gênero, além disso, também surgem novas formas de pensar a cultura, o conhecimento, o poder, a educação (Louro, 2018, p. 44)". Refletindo em torno dessas questões percebemos a quão normalizadora é a escola e em como ela não está preparada para receber os "novos" sujeitos. Precisamos de uma pedagogia e um currículo queer, com novas formas de pensar a educação, a partir das identidades, das diferenças e diversidades, considerando os "novos" sujeitos que estão transitando e tantos outros que estão emergindo, um novo processo formativo.

\section{Descobrimento dos corpos: "meu corpo sempre foi afeminado"}

Nas sociedades contemporâneas, a sexualidade tem sido colocada no centro das discussões, devido ao fato de que nas últimas décadas ter se tornado objeto de estudo e crítica de distintas áreas do conhecimento. Por isso, tem buscado ser decifrada, compreendida, quantificada, rotulada, educada, normalizada (Louro, 2018). As instituições sociais como a igreja, o Estado, a ciência, a escola, buscam também as mais diversas formas para impor uma normalização, na busca de tentar "conter" o atual momento, momento este onde as "minorias" estão mais visíveis, ou melhor, fingem não ver, insistem em negar os corpos plurais que por elas transitam.

Essas instituições precisam a todo momento reafirmar, regular e materializar essas normas, controlar os corpos. "Os corpos não se conformam, nunca, completamente, às normas pelas quais sua materialização é imposta” (Butler, 2003, p. 54). 0 corpo é resistência, é luta. Um corpo não é só um corpo, é resistir diante às normas, os padrões impostos, é através dele que os sujeitos imprimem e mostram suas identidades nas mais diversas formas. 0 corpo fala por si só, ele impõe as diversidades, conversa com a sociedade apenas estando ali e isso incomoda, principalmente se este corpo estiver atravessado pelas intersecções de gênero, sexualidade, raça, classe, religiosidade.

Historicamente no processo de constituição do corpo há toda uma construção daquilo que é tido como adequado a cada gênero. Ainda durante a gravidez é comum ouvirmos a pergunta: é menino ou é menina? Tal indagação faz que aqueles/as que acompanharam esse momento imprimam expectativas e construções de acordo com o descobrimento do sexo do bebê.

Com o nascimento e crescimento da criança isso se intensifica. A infância é atravessada por cores, brincadeiras, desenhos, comportamentos determinados e construídos socialmente. Sobre isso Gustavo Cazumba (2020), relata que: "desde pequeno eu tinha os jeitos, minhas amizades eram só com meninas, só brincava com menina, e painho sempre reclamava, disse que eu não tinha amigo menino, que eu era diferente". Natan Sítio (2020), também relatou experiências parecidas ao afirmar que: "Desde pequeno, mas muito pequeno mesmo, eu era bem afeminado, meu corpo sempre foi afeminado". Na infância, quando as expectativas construídas para cada sexo não são atendidas, inicia-se o conflito, principalmente interno, por colocarem a criança como infrator da norma, como o estranho (Rios \& Dias, 2020).

A partir daí, cresce a discriminação, em forma de piadinhas, brincadeiras homofóbicas, risadas, exclusão, tanto por parte não só da família, quanto dos/as amigos/as amigos, da comunidade, da escola. Rios e Dias (2020, p.6) afirmam: "se reconh ecer no próprio corpo é, sem dúvida, o primeiro grande desafio de meninos que se percebem gays ainda na infância". 
Gustavo Cazumba (2020), salientou: "estou começando a me descobrir agora, às vezes eu não sei o que realmente eu sou... risos. Se sou gay, se sou bi, se sou pan, porque é muito louco, às vezes eu fico sem me entender". Já Natan Sítio ressaltou: "Me reconheço como gay, mas um gay mais afeminado. E... como posso dizer? Quando se é gay afeminado você é mais discriminado".

A partir das falas é possível evidenciar o quanto é doloroso, confuso e conflituoso se perceber enquanto gay, enquanto queer, no espaço rural. Desconstruir tudo aquilo que sempre foi dito como o correto, o "normal", se ver neste lugar de desviante, transgressor, principalmente por ir além da homossexualidade. Se perceber enquanto bissexual, pansexual, como uma patologia na maioria das vezes, segundo Gustavo Cazumba (2020), "nas comunidades rurais têm muitas pessoas que não entendem isso e tratam como se fosse uma doença". Entendemos, portanto, que se há desafios inerentes as questões de gênero, sexualidade, diversidade sexual a serem supurados pela escola, esses desafios se tornam ainda maiores quando refletimos acerca de tais temas a partir da Educação do Campo.

\section{CONCLUSÃo}

Considerando as pesquisas já realizadas e suscitadas por nós nesse estudo e as narrativas de Gustavo Cazumba e Natan Sítio é perceptível que problematizar as questões de gênero e diversidade sexual na Educação do Campo, se constitui num ato de luta e resistência política, ainda em construção, mas indispensável. As mudanças estão acontecendo, os sujeitos estão lá, presentes também nas comunidades campesinas, é necessário superar os discursos apenas dos binarismos e compreender que existem as mais diversas pluralidades de gênero e sexuais. Conforme ressaltou Gustavo Cazumba (2020): "nas comunidades rurais têm muitas pessoas que não entendem as questões de gênero, orientação sexual e tratam como se fosse uma doença".

Rios e Dias (2017) compreendem que, no enfrentamento ao preconceito, no tocante à homossexualidade, é necessário desenvolver políticas de formação centradas nas dimensões pessoal e profissional. Aproximando tais discussões, é inegável como a escola tem contribuído para o reforço de estereótipos, intensificando o preconceito, silenciando corpos, na atual sociedade.

As instituições sociais estão preocupadas com uma "moral" que visa guardar, modelos de famílias e corpos condicionados às normas, descolonizar e desconstruir esses corpos, essas mentes é algo ameaçador. Nesse sentido, os paradigmas são territórios teóricos e políticos que contribuem para transformar a realidade.

A partir de tais pressupostos é possível argumentar que há um novo paradigma a ser considerado, que anseia por novas construções, baseadas em uma sociedade queer, onde ser diferente não é associado a patologia, não é motivo de chacota e até punições mais severas. Uma sociedade que comtemple as mais diversas formas de gênero, diversidade sexuais, sejam elas, no campo, na cidade, nas igrejas, nas escolas, independente da sua etnia, religião, nacionalidade.

\section{AGRADECIMENTOS}

Aos discentes Gustavo Cazumba e Natan Sítio por terem colaborado com este estudo.

\section{CONTRIBUIÇÕES DOS AUTORES}

Thaynara Oliveira da Silva: coletou a narrativa de Gustavo Cazumba; escreveu a metodologia, parte das análises de dados; contribuiu com a produção das considerações. Pedro Paulo Souza Rios: coletou a narrativa de Natan Sítio; escreveu parte das análises de dados; contribuiu com a escrita das considerações. 
Os autores declaram que não há conflitos de interesse.

\section{REFERENCIAS}

Benjamin, W. (1985). 0 narrador: considerações sobre a obra de Nikolai Leskov. In: Benjamin, W. Magia e Técnica, arte e política: Ensaios sobre literatura e história da cultura. São Paulo: Brasiliense.

Brasil. (1996). Lei de Diretrizes e Bases da Educação Nacional. Lei número 9394, 20 de dezembro de 1996.

Brasil. Organização Pan-americana de Saúde. Acessado em 19 de outubro de 2020. https://www.paho.org/bra/index.php?option=com content\&view=article\&id=6120:omsafirma-que-covid-19-e-agora-caracterizada-como-pandemia\&Itemid=812

Brito, C. D. A. \& Nunes, C. P. (2020). The intensification of teaching work in the context of the commercialization of higher education in Brazil. Journal of Research and Knowledge Spreading, 1(1), e11420. https://doi.org/10.20952/jrks1111420

Butler, J. (2003). Problemas de gênero: feminismo e subversão da identidade. Rio de Janeiro: Civilização Brasileira.

Caetano, M. R. Vale. (2016). Performatividades reguladas: heteronormatividade, narrativas biográficas e educação. Curitiba: Appris Editora.

Dashti, E. (2020). Examining the relationship between unwillingness to translate and personality type of Iranian translation students. Journal of Research and Knowledge Spreading, 2020, 1(1), e11467. https://doi.org/10.20952/jrks1111467

Dias, A. F., Cardoso, H. de M., Santos, A. L. dos, Menezes, C. A. A., \& Rios, P. P. S. (2017). Schooling and subversions of gender. Revista Tempos e Espaços em Educação, 10(22), 83-92. https://doi.org/10.20952/revtee.v10i22.6433

Dias, A. F., \& Menezes, C. A. A. (2017). Que inovação pedagógica a pedagogia queer propõe ao currículo escolar?. Revista Tempos e Espaços em Educação, 10(23), 37-48.

Dias, A. F. (2020). Trans* escrevivências as a pedagogical power. Journal of Research and Knowledge Spreading, 1(1), e11494. https://doi.org/10.20952/jrks1111494

Ebrahimi, M. A. (2020). Cultural value of translation of proverbs and synopsis. Journal of Research and Knowledge Spreading, 1(1), e11484. https://doi.org/10.20952/jrks1111484

Fernandes, B. M.; Molina, M. C. (2004). Contribuições para a construção de um projeto de Educação do Campo / Mônica Castagna Molina e Sônia Meire Santos Azevedo de Jesus (organizadoras). Brasília, DF: Articulação Nacional "Por Uma Educação do Campo, Coleção Por Uma Educação do Campo, p. 32-52.

Fischer, I. R. (2006). O protagonismo da mulher rural no contexto da dominação. Recife: Massangana. 
Hage, S. (2005). A importância da articulação da identidade e pela educação do campo na construção da identidade e pela luta da educação do campo. Texto apresentado no I Encontro de formação dos Educadores do Campo do Nordeste Paraense, realizado em Bragança.

Heckler, V., Fazio, A. A. \& Ruas, F. P. (2020). Investigation with experimental practical activities in training geographically distant teachers. Journal of Research and Knowledge Spreading, 1(1), e11403. https://doi.org/10.20952/jrks1111403

Josso, M. C. (2006). Os relatos de histórias de vida como desvelamento dos desafios existenciais da formação e do conhecimento: destinos sócio-culturais e projetos de vida programados na invenção de si. In: Tempos, narrativas e ficções: a invenção de si. Porto Alegre: EDIPUCRS.

Junqueira, R. D. (2013). Pedagogia do armário: a normatividade em ação. Revista Retratos da Escola, 7(13): 481-498.

Louro, G. L. (1999). Pedagogias da sexualidade. In: Louro, G. L. (Org.). O corpo educado: pedagogias da sexualidade. Belo Horizonte: Autêntica.

Louro, G. L. (2014). Gênero, sexualidade e educação: uma perspectiva pós-estruturalista. Rio de Janeiro: Vozes.

Louro, G. L. (2018). Um corpo estranho: Ensaios sobre sexualidade e teoria queer. Belo horizonte: Autêntica Editora.

Lucena, S., \& Oliveira, J. M. A. (2014). Culturas digitais na educação do Século XXI. Revista Tempos e Espaços em Educação, 7(14): 35-44.

Maknamara, M. (1). Narrativas (auto)biográficas e necessidades formativas de futuros docentes de ciências: reflexões preliminares para um objeto em construção. Revista Tempos e Espaços em Educação, 8(16): 99-108.

Nascimento, L. F. do, \& Cavalcante, M. M. D. (2018). Abordagem quantitativa na pesquisa em educação: investigações no cotidiano escolar. Revista Tempos e Espaços em Educação, 11(25), 249-260.

Nóvoa, A. (2000). Os professores e as histórias da sua vida. In: (Org). Vidas de professores. Porto: Porto.

Paiva, C. C. S. \& Barros, E. R. (2017). Paradigma Cultural II: gênero, educação, trabalho e etnias. Curitiba: CRV.

Paraskeva, J. M. (2016). "Brutti, Sporchi \& Cattivi”: Towards a Non-Abyssal Curriculum. Revista Tempos e Espaços em Educação, 9(18), 75-90.

Pereira, A. (2018). A educação de jovens e adultos no sistema prisional brasileiro: o que dizem os planos estaduais de educação em prisões?. Revista Tempos e Espaços em Educação, 11(24), 245-252.

Pedro, N. (2017). Ambientes educativos inovadores: o estudo do fator espaço nas 'salas de aula do futuro' portuguesas. Revista Tempos e Espaços em Educação, 10(23), 99-108. 
Pinto, E. J. S. et al. (2017). As relações de gênero nas escolhas de cursos superiores. Revista Tempos e Espaços em Educação, 10(22), 47-58.

Rios, P. P. S. (2016). Da terra seca brota uma flor: relação de gênero e educação no contexto Semiárido. Curitiba: CRV.

Rios, P. P. S., Dias, A. F., \& Brazão, J. P. G. (2019). "Lembro-me de querer andar durinho, como se diz que homem deve ser": a construção do corpo gay na escola. Revista Exitus, 9, 775-804.

Rios, P. P. S., \& Dias, A. F. (2017). Trajetórias de vida de professores homossexuais no semiárido brasileiro: as narrativas (auto) biográficas enquanto instrumento de formação docente. In. PAIVA, C.C. da S.; BARROS, E. da R. (Org.). Paradigma Cultural II: gênero, educação, trabalho e etnia. Curitiba - CRV.

Rios, P. P. S., \& Dias, A. F. (2019). "Então me classificavam como estranho": entre narrativas na construção do estranho no corpo de professores gays. Revista Brasileira de Pesquisa (Auto)Biográfica, 4(11): 539-557.

Rios, P. P. S., \& Dias, A. F. (2020). "Nossa história de vida é construída a partir do nosso corpo": a produção do corpo viado na docência. Revista Ibero-Americana de Estudos em Educação, 15(3): 1265-1283. https://doi.org/10.21723/riaee.v15i3.13574

Santos, H. T., \& Garms, G. M. Z. (2014). Método autobiográfico e metodologia de narrativas: contribuições, especificidades e possibilidades para pesquisa e formação pessoal/profissional de professores. Disponível em:

http://200.145.6.217/proceedings arquivos/ArtigosCongressoEducadores/364.pdf

Santos, I. T. R., Barreto, D. A. B. \& Soares, C. V. C. O. (2020). Formative assessment in the classroom: the dialogue between teachers and students. Journal of Research and Knowledge Spreading, 1(1), e11483. https://doi.org/10.20952/jrks1111483

Scott, J. (1998). Gênero: uma categoria útil de análise histórica. Educação e Realidade, 20(2): 645-670.

Seffener, F. (2009). Sexualidade: isso é mesmo matéria escolar? Rev. Teoria e Prática da Educação, 17(2): 67-81.

Souza, E. C. (2006). A arte de contar e trocar experiências: reflexões teórico- metodológicas sobre história de vida em formação. Revista Educação em Questão, 25(11): 22-39. 